\title{
Pré-teste do Jogo de Trilha - Lixo Amigo: ensino didático da responsabilidade social e ambiental
}

\section{Pre-test of the track game - friendly garbage: didatic teaching of social and environmental responsability}

Patricia Soares Rocha Alves ${ }^{1}$ | radarsul@gmail.com

Denise Celeste Godoy de Andrade Rodrigues ${ }^{2}$

\begin{abstract}
RESUMO
Este artigo tem como objetivo relatar como foi a aplicação do projeto piloto do produto de dissertação do Mestrado Profissional em Ensino em Ciências da Saúde e do Meio Ambiente. O tema da pesquisa é a coleta seletiva de lixo e educação ambiental que resultou no desenvolvimento de um jogo, denominado "Lixo Amigo. O pré-teste foi realizado no colégio particular Interativo, em Volta Redonda e foi aplicado para uma turma de 3 ano do ensino fundamental. O tema principal do jogo é a preocupação com o meio ambiente através da mudança de hábito das pessoas em relação ao lixo. Acredita-se que o fato de as pessoas não acondicionarem o lixo de maneira correta, seja uma questão cultural, falta de costume ou de informação do benefício que essa atitude possa trazer para o meio ambiente. Através da aplicação do jogo para as crianças acredita-se que estaremos iniciando uma pequena mudança de hábito em relação ao lixo. A avaliação do produto foi feita através de questionário entregue à professora da turma.
\end{abstract}

Palavras-chave: Coleta Seletiva; Didática; Meio Ambiente; Ensino Fundamental

\section{ABSTRACT}

This article aims to report as was the application of the pilot product of the dissertation Professional Masters in Teaching of Health and Environment. The research topic is the garbage collection and environmental education has resulted in the development of a game called "Trash Friend. The pretest was conducted in private school Interactive, in Volta Redonda and was applied to a class of three years of elementary school. The main theme of the game is the concern for the environment by changing habits of people in relation to waste. It is believed that the fact that people do not acondicionarem garbage correctly, is a cultural issue, lack of practice or information benefit that can bring this attitude to the environment. By applying the set for the children we believe that a small change of initiating habit in relation to the waste. The product evaluation was done through a questionnaire delivered to the classroom teacher.

Keywords: Selective Collection, Curriculum, Environment, Elementary Education

1 UniFOA - Centro Universitário de Volta Redonda, Volta Redonda, RJ.

2 UERJ - Universidade do Estado do Rio de Janeiro, Resende, RJ. 


\section{INTRODUÇÃO}

A maior parte da população brasileira vive em cidades e pode-se observar uma crescente degradação das condições de vida, refletindo uma crise ambiental. Percebe-se então, que é necessário refletir sobre os desafios para mudar as formas de pensar e agir em torno da questão ambiental numa pespectiva contemporânea (JACOBI, 2003, p. 190).

Objetivando-se contribuir para a educação ambiental nas escolas, introduzindo a temática da separação correta do lixo, foi proposto neste trabalho a utilização do jogo educativo Lixo Amigo como material paradidático em sala de aula.

Essa cultura deve ser mudada na escola, mostrando às crianças e jovens que conservar o meio ambiente não é um luxo, mas uma necessidade urgente, se quisermos continuar a viver neste planeta. A fim de tentar fazer dos temas ambientais presença constante nas salas de aula, é importante se trabalhar com conteúdos voltados à Educação Ambiental (Narcizo, 2009). Para Gularte (2010), os jogos educativos além de oferecerem desafios, têm como objetivo, agregar conhecimento educacional aos jogadores, ensinando algo. Dessa forma, os jogos educativos proporcionam aquisição de conhecimento à medida que o jogador vai avançando no jogo.

\section{OBJETIVO}

Conscientizar as crianças através do jogo Lixo Amigo sobre a forma correta e a importância da realização da coleta seletiva de lixo.

\section{METODOLOGIA}

A abordagem da pesquisa foi qualitativa, baseada no ensino da educação ambiental, com foco na coleta seletiva de lixo para crianças do Ensino Fundamental, sendo devidamente aprovada pelo Comitê de Ética em Pesquisa Envolvendo Seres Humanos sob número CAAE 08246512.8.0000.5237.

Para a confecção do jogo, foram realizadas pesquisas de material, matéria prima, layouts, análise cromática, estudo de tipografias, para se obter um resultado final atrativo, de fácil leitura e entendimento. Foram feitos testes de peso e formato com os materiais pesquisados para ver qual deles melhor se adaptava ao objetivo do jogo.

O jogo piloto do pré-teste Lixo Amigo é composto de um tabuleiro em formato de lona, alvo em PVC e 44 cartas. Além de quatro peões e abadás coloridos com as cores que remetem à coleta seletiva. Esta primeira versão foi aplicada em uma turma do ensino fundamental de uma escola privada localizada no Município de Volta Redonda.

\section{RESULTADOS}

O jogo foi aplicado pela professora, que assinou o termo de consentimento livre e esclarecido, assim como os responsáveis dos 24 alunos, sendo 12 meninas e 12 meninos, e respondeu o questionário semiestruturado. O jogo foi aplicado no pátio da escola, como mostrado na Figura 1. 


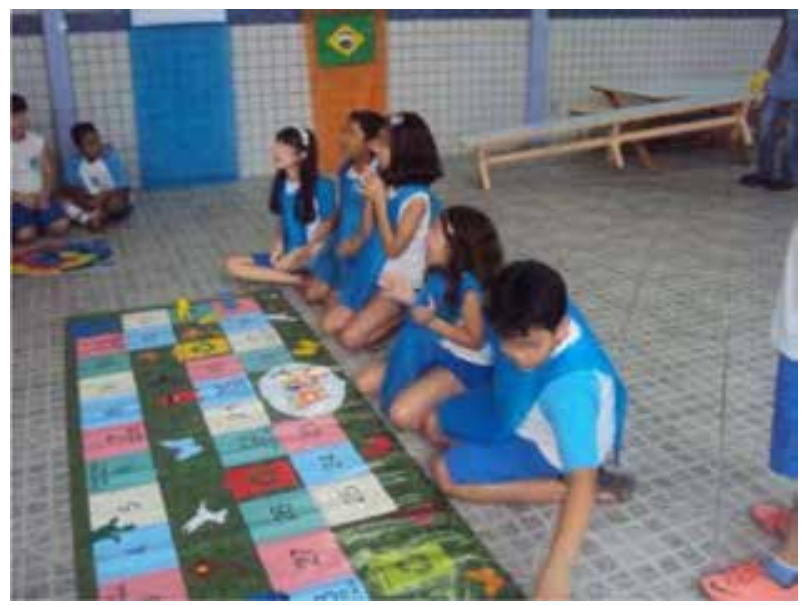

Figura 1: Crianças atentas a explicação da professora

O que se pôde observar durante a aplicação do jogo foi um total entrosamento entre os alunos , a professora e o a dinâmica do jogo (Figura 2 e Figura 3).

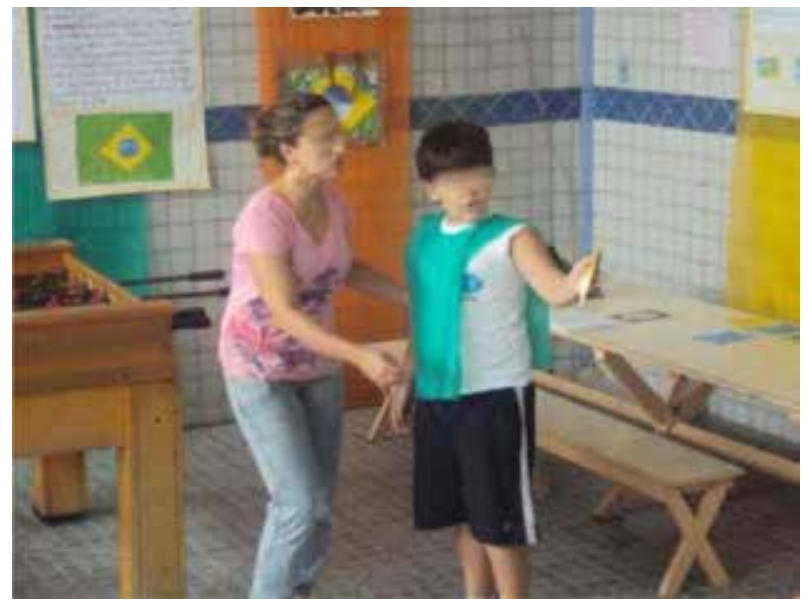

Figura 2: Aluno lendo a carta com informações de reciclagem

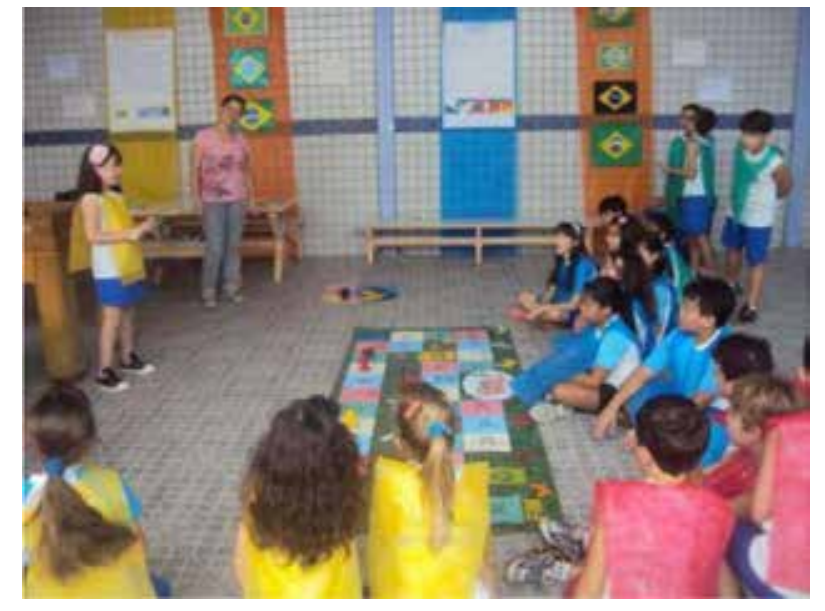

Figura 3: Dinâmica do jogo com a professora e os alunos.

A separação dos grupos por abadás coloridos proporcionou um espírito de equipe na turma, com muita torcida. O que foi muito interessante é que no decorrer da partida um grupo solicitou à professora que se desse tempo na aula, pois elas queriam jogar outra partida, uma vez que elas estavam perdendo e queriam jogar de novo para tentar ganhar.

Alunos de outros anos passavam pelo pátio onde foi feito o teste e questionavam a professora, o porquê deles também não estarem jogando. Como regra do jogo quem chegar primeiro ao final da trilha, ganha e acaba o jogo. Mas os alunos pediram para a professora continuar a partida, pois queriam ver quem iria ficar em segundo, terceiro e quarto lugares. Apesar dessa competitividade ao final quando todos os grupos perceberam que só quem tinha chegado em primeiro lugar poderia tirar a carta do artesanato para confeção do brinquedo, acharam tão interessante que pediram para ver as outras cartas e solicitaram que os grupos escolhessem também outros brinquedos.

Segundo relato da professora da turma em resposta ao questionário em relação as regras do jogo, observou-se que seria melhor que as cartas ficassem umas em cima das outras colocando por baixo as que já foram lidas ao invés de ficarem espalhadas, (Figura 4), uma vez que receou que cartas da pilha acabassem. 


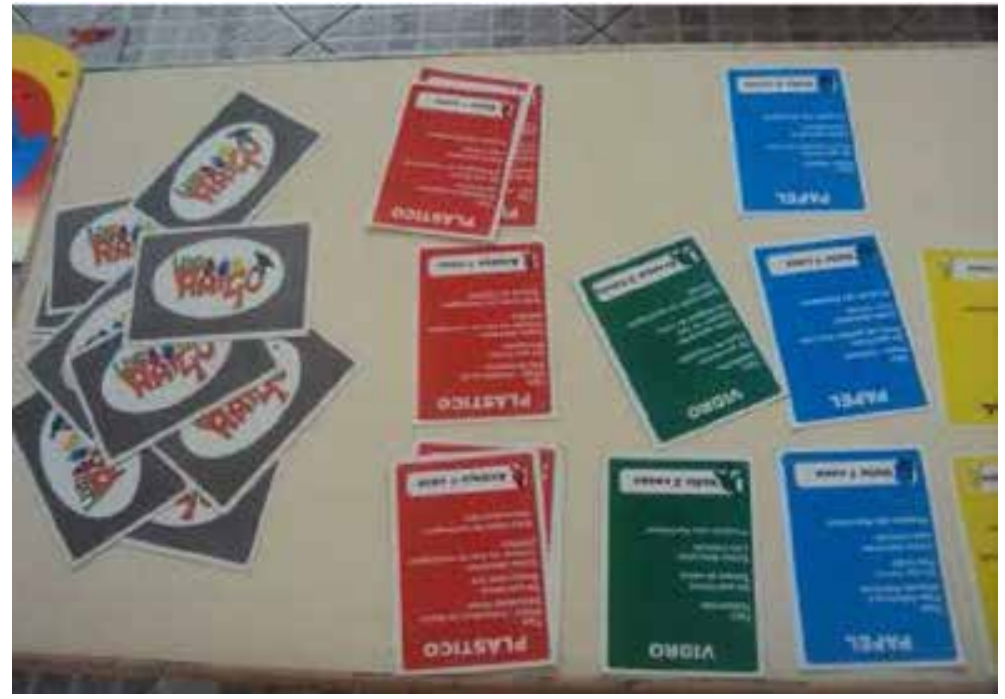

Figura 4: Cartas do jogo durante a partida.

Com relação ao alvo, o estudo do dardo não deu certo por questões de tipo de material e de fixação. Optou-se então por utilizar uma meia com areia que era lançada no alvo, disposto no chão. Esta alternativa não deu muito certo, pois a meia rolava muito e passava do alvo (Figura 5). Essa questão terá que ser repensada para a aplicação do jogo nas outras turmas.

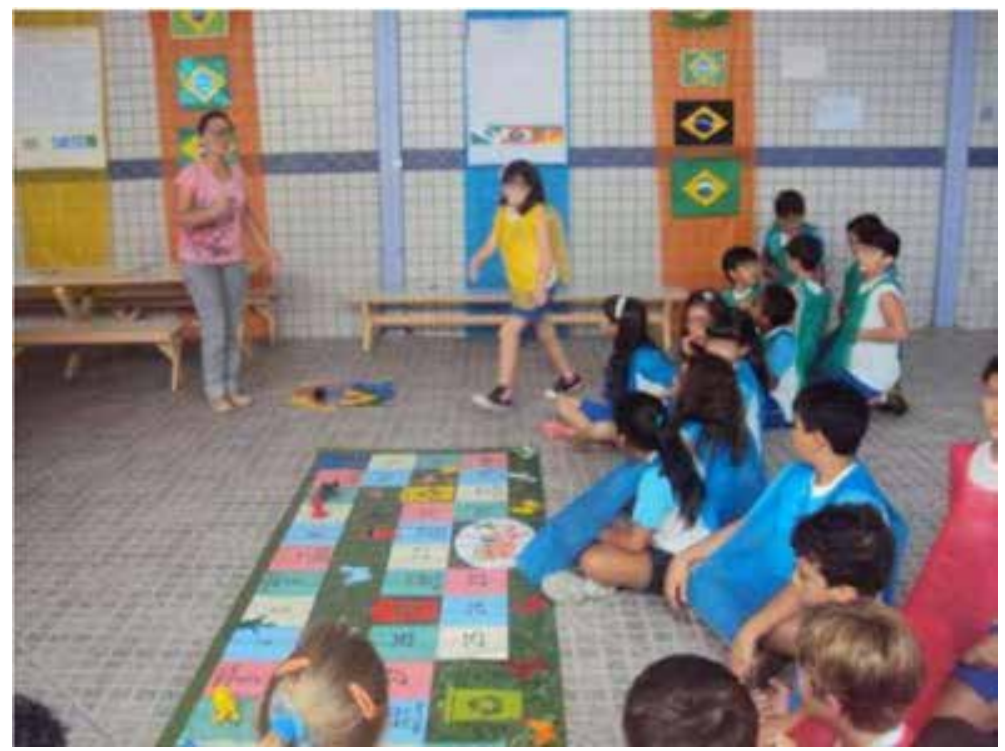

Figura 5: Momento onde a aluna acerta o alvo

Os peões feitos de resina não suportaram a empolgação das crianças que ao segurarem andavam com eles pela trilha batendo com muita força na lona o que acabou quebrando o pé da latinha amarela (Figura 6). 


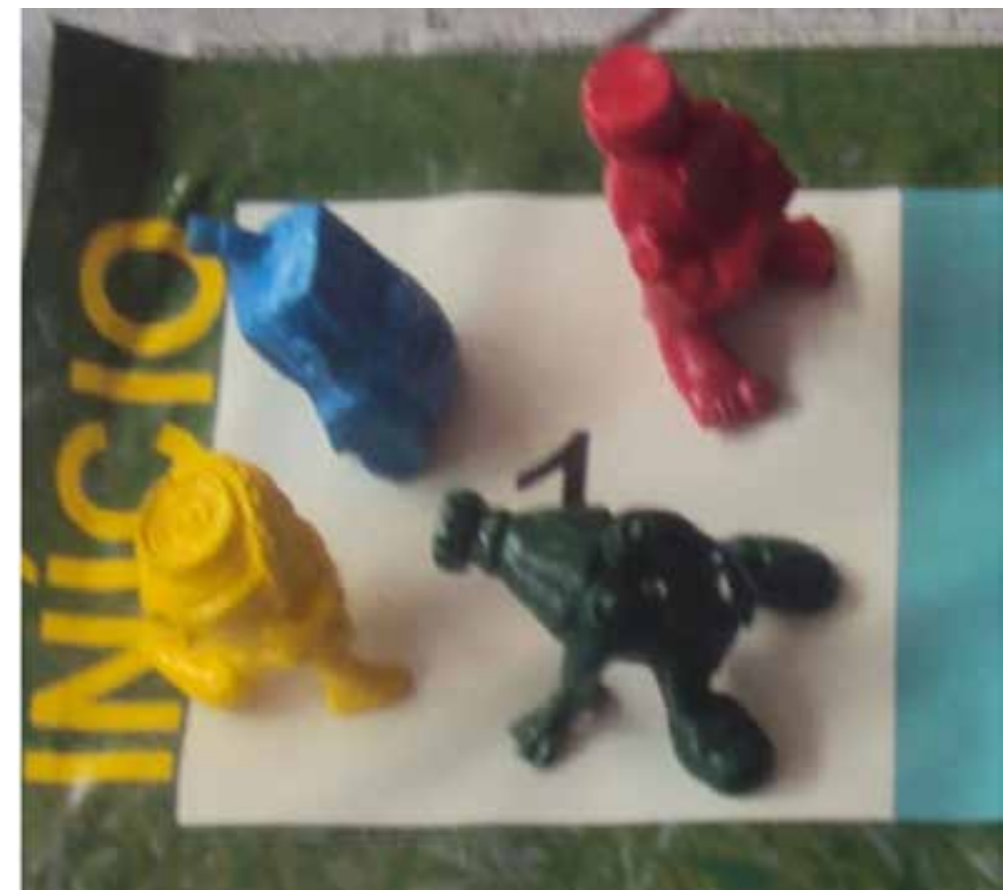

Figura 6: Imagem dos peões de resina durante a aplicação do jogo.

Para que isso não ocorra mais, pensou-se em colocar os peões dentro de garrafas PETS transparentes, com suporte de isopor para protegê-los, estas ficariam também mais altas, observou-se que os peões ficaram um pouco pequenos em relação ao tamanho da lona.

Em relação ao texto das cartas as crianças se saíram muito bem, leram para a turma e ficaram surpresas ao perceberem como devem ser descartados os materiais que elas usam no seu cotidiano. Após escolherem dois tipos de brinquedos a serem confecionados, a turma na semana seguinte trouxe o material e realizaram a confeção do jogo da velha e cai-não-cai. Foi muito interessante observar que a confeção foi feital independente e sem o auxilio da professora demostrando a facilidade de se fazer brinquedos com material reciclado conforme Figura 7.

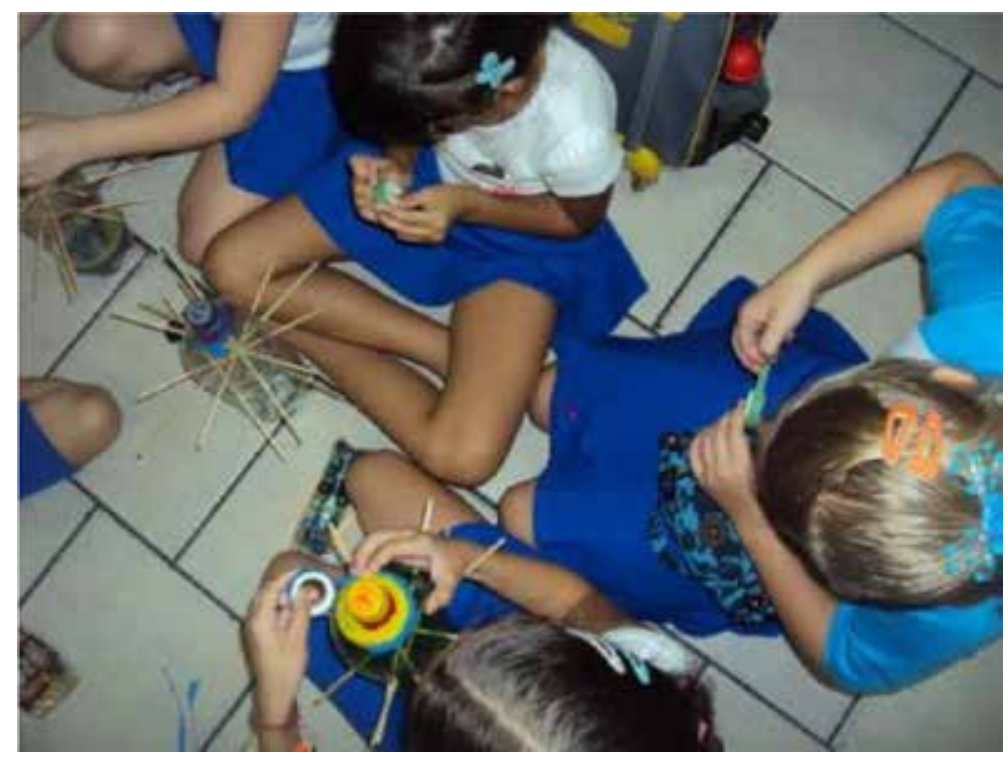

Figura 7 Confecção do cai-não cai com garrafa Pet. 


\section{CONCLUSÃO}

Observou-se que este pré-teste serviu para o aprimoramento do jogo e foi de extrema relevância para a conclusão da execução do jogo final.

O bom pesquisador deve aceitar as mudanças de propostas como um benefício de crescimento para o estudo. Para avaliar se as modificações no jogo foram bem aceitas pelas crianças e se realmente irá atingir o objetivo proposto, serão feitos ainda testes em duas escolas, uma particular e outra municipal, com mais 9 turmas totalizando uma média de 250 alunos do ensino fundamental do $1^{\circ}$ ao $5^{\circ}$ ano, para verificar a faixa etária a que o jogo se aplicará melhor.

Os jogos, quando bem elaborados e orientados corretamente pelo professor, servem de estímulo ao aprendizado, como uma ferramenta pedagógica atrativa para adquirir um novo conhecimento.

\section{BIBLIOGRAFIA}

JACOBI, P. Educação ambiental, cidadania e sustentabilidade. Cadernos de Pesquisa. n.118, p. 189 - 205, 2003. Disponível em: http://www.scielo.br/pdf/cp/n118/16834.pdf. Acesso em julho de 2012.

NARCIZO, K. R. S. Uma análise sobre a importância de trabalhar educação ambiental nas escolas. Programa de Pós-Graduação em Educação Ambiental. Revista eletrônica Mestrado em Educação Ambiental. ISSN 15171256, v. 22, janeiro a julho de 2009. Universidade Federal do Rio Grande - FURG.(p - 89) Disponível em: <http://www.remea.furg.br/edicoes/vol22/art6v22.pdf>. Acesso em dez de 2012.

GULARTE, D. Jogos eletrônicos: 50 anos de interação e diversão. Teresópolis: Novas ideias, 2010. 